\title{
GENEALOGICAL GEOGRAPHY: PLACE IDENTIFICATION IN THE MAP LIBRARY*
}

\author{
By William H. Lamble
}

\begin{abstract}
This paper examines the factors, which govern identification of place in its environment, its literature and its description as presented to the reference librarian by the genealogical researcher. The concept of place seems a simple enough idea, but the more it is studied the greater grows the realisation of its complexity. The study of toponymy becomes more necessary in the effective identification of place and the retrieval of required spatial data.

Toponyms and exonyms, their elements of activity, status, extent, focus and boundaries are examined, explicated and defined. The techniques, sources and tools needed by the map and geography librarian to provide adequate services to genealogical researchers are considered, together with the researchers' varying levels of carto-literacy and the accuracy of their source documents in identifying place.
\end{abstract}

\section{Introduction}

One major and very popular approach to enlightenment is family history research. Map libraries form essential gateways to achieving such enlightenment. This paper is based on years of experience as a map librarian answering enquiries from genealogical researchers. The wording of such enquiries would be very precise but for a number of reasons, as I shall explain, ineffective in information retrieval from the normal descriptive sources of a library's collection. Enquiries were complicated by the fact that there appeared to be a multiplicity of vocabularies used - by geographers, cataloguers, other librarians and the readers themselves. Place name requests were generated from documents which may have corrupted the specific place name recorded and have not related the place to the jurisdiction involved and rarely linked other relevant jurisdictions. Hierarchies in geographical identification are difficult to establish both in "jurisdictional" and "status" orders. The terminology prescribed in LCSH (Library of Congress List of Subject Headings) is at odds with the international jargon of geographical terms and in many cases is imprecise. Precision is made more difficult by temporal changes in nomenclature and geographical location or extent. This paper draws from a number of presentations made to family history groups and is part of a

Paper presented at International Federation of Library Associations (IFLA), 65th IFLA Council and General Conference Bangkok, Thailand, August 20 - August 28, 1999 
more intensive investigation into geographic classification and cartobibliographical information retrieval.

In much of the paper I am referring to traditional hard copy maps. As historical information is the objective of genealogical research, most of the maps required will be older and not likely to be available in digitised form. Modern technology allows the creation of maps in layers, and the user can choose the layers of information required. The number of layers available on one screen is however limited by readability. Hard copy maps and also those earlier maps which have been scanned and digitised do not at the moment allow separation of layers.

\section{The Question of Place}

One of the most frequently asked questions is phrased as "Where are you from?" or "Where do you live?" This is one of the most difficult questions to answer simply and in a meaningful way. This emphasises the point that we are not place specific in our everyday living and that our reference terminology for places is never consistent, neither exclusive nor inclusive The range of overlapping areas in which we live comprise:

State

Metropolitan Area

Local Government Area or Ward

Suburb

Locality

Postal District

School catchment district

Electoral District or Division or Province

Natural region

Telephone exchange district

Religious district - Parish, Deanery or Diocese

Census District

Etc.

\section{Determinants of Location Description and Identification}

There are a number of factors involved in identifying place. Location is governed by the activity or event considered in that location and the location also has a status. The location is circumscribed by a boundary and has a focal point and may also have temporal limitations. These factors are not spatially or temporarily exclusive and the specific locations will often overlap or coincide, as I 
demonstrate below. However, before studying the factors in detail it is necessary to consider three aspects used in the transfer of locational information.

Official usage may be prescribed - as is often the case currently due to the existence of official geographical nomenclature authorities, or may be accepted through patterns of long usage. On the other hand names are often applied for commercial reasons without meeting the strictures of or acceptance by the authorities. There is also the weight of popular tradition, which has restricted accurate cartography down the ages - but this is another study entirely. The matter is further complicated by the vagaries of mental maps and their inaccuracies, about which much has been written. These last two factors can be described as the common "Worldview" or "Weltbild". Government topographic maps usually only contain official names and these names are used in the compilation of national gazetteers. Other thematic maps, including government maps are not so restrictive, e.g. geological maps and tend to record the popular or vernacular place names with restriction. There is an atlas of Western Australia that contains 34 maps of the State. (Drawing the line/ compiled by J.F. Berry). Each map is a map of the administrative boundaries of divisions of the State adopted by different agencies, Commonwealth, State and Local. Names and boundaries sometimes vary, sometimes not. It seems unbelievable but it is quite logical - there is nothing to stop the absurd being logical.

\section{Activity, Event or Object in Space}

References to location are also effectually references to a particular event or activity as much as an area or an object. I use the terms activity or event with broad meanings. What is shown on the map is either "cultural" or "natural" - these are cartographic jargon terms and on the one hand "artificial, built or human" and on the other "something occurring independently of human intervention". The activity is defined and limited by two things - it has a focal point and a boundary that localises it and attracts a name. We are most concerned in using this aspect when we create or use geographical subdivisions for topical subject headings - but this approach is often misused. A specific geographical location should be described directly by its appropriate name, but allowance for linkage to other forms of the name is required in automated retrieval systems. In indirect subject access, one has to consider if this is for a comprehensive work on the locality (direct access required) or topic specific. If the latter, is it unique for the geopolity (indirect use of locality name) or topic specific for one of a type of localities in a wider geopolity? In the second instance, retrieval requirements indicate that the geographical subdivision should be for the wider geopolity. In a card catalogue it is reasonable to use: 
Stroud (England)-Maps.

Streets-England-Stroud-Maps.

But in an automated catalogue, and these usually search indirect headings, the second heading should be:

Streets-England-Gloucestershire-Maps.

\section{The Status of Place}

Status appears to have a cultural connotation only, but the choice of terms to describe geographical locations must also be applied to natural aspects, as they cannot be divorced from the cultural in any form of spatial data transfer. Terms for natural divisions are more subject to jargon and national language practices. We are all familiar with the concept of mountain ranges, but perhaps are less familiar with the broader term cordillera or orogen. We can readily grasp the term botanical province and most know the word tundra if not taiga or other regional descriptors.

It is when we consider the human aspect that the system becomes complicated, both hierarchically and jurisdictionally. Terms used are:

Populated places
Townlands
Towns
Cities
Urban areas
Villages
Parishes
Hamlets
Etc.

The areas encompassed by these settlements have evolved in the case of "old world" countries and to a certain extent devolved before resuming evolution in the ex-colonial countries. Town plans were created on square mile blocks in North America and "county" or "shire" boundaries drawn by straight lines on a blank map before settlement. The matter of territoriality derived from aristocratic titles and the associated landholdings will be dealt with later. In retrieving information about a specific location it is important to recognise status as this can determine the wider geographical area to be used as an access term for searching.

\section{Jurisdiction}

For the genealogist a major purpose is to locate the jurisdictional repository for documentary records as well as locating events on the map. Subject classifiers and 
cataloguers blithely use the term jurisdiction to create and apply hierarchical subject headings and classification notation as if this is a unique and exhaustive method of handling the problem. Reference practice requires the supplementation by gazetteers and historical topographic dictionaries and histories to determine bibliographical search terms. Jurisdictions are not a simple and single identification process. Constitutionally these are defined in acts which separate, allocate and delegate powers politically, administratively and ecclesiastically, creating "tiers of government. Jurisdiction is a subdivision of activity and to meet the needs of the researcher both the location of an event and the appropriate jurisdictions in which it is sited are to be identified. When considering the ecclesiastical nature of jurisdiction, attention must be paid to the differing practices of the Roman Catholic and Anglican Churches. The former names dioceses by their extent while the latter by their cathedral city - although the territory administered may be the same, e.g. Sees of Iceland (Catholic) and Reykjavik (Anglican).

\section{Boundaries and focal points}

Every activity has a focal point and its area is circumscribed by boundaries. With the passage of time areas expand and the boundaries change. When I first moved to Perth, Western Australia in 1961 the Perth Metropolitan Area was considered to be that area within a 20-mile (32-km) radius of the Perth General Post Office. This latter is considered the geographical focus for the area, consisting of the City of Perth and a number of cities, towns and road districts (now called shires). Today the Metropolitan Area now extends $105 \mathrm{~km}$ from north to south and $60 \mathrm{~km}$ from West to East. By 2005 the north to south extent will be $175 \mathrm{~km}$, several rural shires and even all or major portions of some previously non-metropolitan regions being absorbed by the growing conurbation. This is not an isolated example of global urbanisation. Natural features generally have stable and recognised boundaries, human boundaries have either evolved or devolved to correspond to natural obstacles which form good defences although this stricture is not always so compelling nowadays.

Laws governing the distribution of electoral divisions are a rare but useful example of the definition of a community and its boundaries is to be found in the Commonwealth Electoral Act of Australia:

"(a) community of interests within the Division, including economic, social and regional interests;

(b) means of communication and travel within the Division;

(c) the trend of population changes within the State;

(d) the physical features of the Division; and

(e) existing boundaries of Divisions and Subdivisions." 
Statutory terms of reference demonstrate the nature of specified place, but are complicated by the need to equalise as far as possible the population numbers within each division. This, of course, does cause some distortion in regard to meeting the other requirements.

The focal point of any area is dependent on the activity. Cathedrals, town halls, schools, shopping centres, to give a few examples, can all be focal points for activities that have the name in common, a portion of the same territory but different boundaries. Shopping centres in particular may have quite a catchment area in relation to the community in which it is situated. The example of map sheet titles is interesting. The Landranger maps at a scale of 1:50 000 of the British Ordnance Survey each cover an area $40 \mathrm{x} 40 \mathrm{~km}$. and are centred on the major feature or group of features covered by the map and uses these for its title. The International map of the world at a scale of 1:1 000000 and the Australian topographic series at a scale of 1:100 000 are based on a grid formed by the use of geographical co-ordinates, $6 \times 4$ degrees for the IMW and 30 minutes for the Australian series. The Perth Metropolitan area appears in both series split into northern and southern parts, respectively in the bottom left and the top left hand corners of two sheets. The IMW sheets are titled Perth and Albany; the Australian maps are titled Perth and Fremantle. In neither case do the sheet titles demonstrate the area covered by the map sheets nor do they automatically present identification of the boundaries.

\section{History of Human Settlement Development and Identification}

As I have already mentioned human habitations have either evolved or devolved. Nomad civilisations are not considered to have had fixed settlements but they did have favoured grazing and hunting areas camping and wintering areas and there was competition for these. Not only would there have been some form of identification but also a necessity for defence. In identifying places we find the first emergence of place name elements - words which describe the nature or quality of the place. Current modern examples are -field, -up or -ville, but they are not just limited to suffixes. The change to agriculture saw the use of more long lasting settlements and these expanded with the growth of trade and industrialisation. Thus places and their name evolved. Conquest in its turn brought enforced changes there are plenty of examples in ancient and modern history. Throughout this process there was also the sense of a focal point for the "activity" with its boundaries.

The 16th century brought a change - colonisation of new worlds. First the Americas, latterly Australasia and to a certain extent Africa. Terra Nullius was a concept embraced in practice if not stated policy. The difference of course was in 
the state of geographical knowledge - maps showed wide-open spaces and there was little indigenous information available as there was in Eurasia. Surveyors drew potential settlements and administrative areas on blank sheets and sent pioneers out to settle and multiply. One only has to look at the county boundary maps of the USA and Australia and the 1 square mile town block plans of US cities to see what I mean. These plans took no heed of natural boundaries and obstacles. The result - a redrawing of boundaries and unplanned population transit contrary to the plans of the colonial powers. It is interesting to see how few of the original counties of Western Australia retain their names, let alone their original boundaries. So we have two patterns of development in settlements - evolution and devolution with both processes reversible after a certain stage of development.

Status evolved as well. To look at English development from the Middle Ages on we must look at the administrative structure. Under the feudal system, land devolved from the crown through an infrastructure of counties, baronies and manors; each level responsible for providing just so much service through to the level above up to the crown. The territoriality of aristocratic titles which originally presupposed jurisdiction are now irrelevant - the Duchy of Cornwall with major landholdings in London is a separate entity from the County of Cornwall (political entity), the Duchies of Devon, Norfolk, Northumberland and Westminster are grounded in Derbyshire, Sussex, London and Cumbria respectively. With the reformation we find a partial democratisation of the upper levels (due to the growth of the merchant class) and the transformation of the manor to the parish - the ecclesiastical parish. It was not until 1824 as part of wholesale legislative measures to cope with the industrial revolution that the civil parish separate from the church parish was created. The two types of parish then developed in their own ways, one depending on population changes, the other on changes to church membership. Names may have been retained or new ones coined - here one is very interested in the status applicable to each place and its name. The exercise in 1972, which caused the County boundary revision in the UK in 1974, has been repeated and boundaries are being changed again. For instance, the former County of Rutland has been restored!

\section{Toponyms and Exonyms}

A toponym is a place name. More specifically it is the officially recognised name of a place within its own jurisdiction. Most countries and states have geographical names authorities who approve the nomenclature for that jurisdiction. They have generally only existed since World War II and have only received formal international recognition since the 1970s. This has not stopped the adoption and usage of unofficial names and there has also been a proliferation of place name changes - for various reasons. The existence of differing official and unofficial 
names has already been mentioned. This however only referred to names within one language community. Considerable international effort through United Nations conferences, global and regional has been made to provide an agreed geographical nomenclature throughout the world. As the toponym is the recognised form of a place name within a polity, so an exonym is the officially recognised usage for place names in another country - London, Londres; Bruxelles, Brussels and Praha, Prague. The OPALINE database of the Bibliotheque nationale de France does provide a solution to this problem in accessing the map collections from a subject approach.

Most official records created more than a 100 years ago were copied from oral reports and this caused errors due to phonetic rendering and speech corruption. "The back of Hill End farm" was corrupted by elision and dialect and ended up on a document as Backhill End in one example I have dealt with. Variant spellings abound for the same pronunciation - Street and Strete. Bristol was originally called Bricg Stowe (place of the bridge), became Bristowe and then because of the local dialect with its terminal L became Bristol. The same happens on the continent, the island of Funnen in Denmark is shown on Danish maps as Fyn.

\section{Toponymy and the History of Place Names}

The history of particular place names is sometimes obvious, sometimes not. There are at least two Colognes. This name developed from the Roman habit of naming settlements (founded in the provinces to settle retired soldiers) Colonia Aggripina or Augustalis, etc, (depending on the then emperor, his heir or favourite). The first became known to the English and French as Cologne, to the Germans as Koln. Political correctness abounds in toponymy. Not only conquest but international rivalry and sensitivity as well as ideology, religions and politics also make their mark. There is a plethora of competing French and German names on the French, German and Swiss border areas e.g. Lorraine or Lotharingia. The Baltic States provide a variety of names in Polish, German, Russian and Slavic. I particularly enjoyed Michener's Poland, which gave an enthralling and readily understandable account of boundary and name changes in Eastern Europe. We must also remember such name changes as St Petersburg, or Petrograd or Leningrad and pay attention to name changes in places like Vietnam.

I have mentioned the move towards authorising names. People have always been contrary and done their own thing. This is very noticeable in the mining areas. Prospectors have consistently named their diggings independently. Some of the names have survived to be recognised and shown on topographic maps. As I have stated above place name indexes are not comprehensive gazetteers and only list officially recognised names. However, they are also subject to human and 
typographical error. Thomsons Brook in W.A. (the official name) appears in the Australian Master place name index as both Thompson Brook and Thomson Brook. However the geological maps are less severe and record most of the unofficial names. Developers are also name providers. Nowadays they are generally well controlled and work within limits set by the Geographic Name Authorities. This was not so in the past. Names for new land releases would be selected for their selling power and gradually be lost, other than on personal records created during their brief life - names almost guaranteed to appear on some of the documentary records cited by family historians and thus used as their search terms. One last difficulty is a process I call creep. A place name moves. When I was in the Air Force in the 1950's I used to go home via Bath (Aqua Sulis = Hot springs to the Romans) and passed successively through Batheaston, Bathhampton and Bathwick - each with their own railway stations (closed in 1956). In the 1970's I was asked to find Bathwick on a map and horrors - a Bathwick House and a Bathwick Road but no Bathwick. Then in the 1980's a new map of Bath shows the locality of Bathwick. Localities may decline, cease to be fashionable and a new area spring up alongside. This goes through the same process and the next new development is named "historically" so a lost name re-emerges but not necessarily in the same spot. I have found aspects of this phenomenon in many areas while researching geographical locations for clients.

\section{The Objectives of the Genealogical Researcher}

Some genealogical researchers are aware of all the objectives in using maps in their research. Having made several presentations to family historians of varying expertise and experience, I have consistently amended or refined my coverage of the subject. Beginners and the less cartographically sophisticated tend only to request a map to show the location of a place mainly as a simple illustration without realising the benefits. However, the main function of map use in genealogical research is its use as a tool in effective pursuit of family history; the production of effective maps to illustrate the compiled family history is often a separate exercise.

The researcher depends upon documentary evidence to support his genealogy. The prime purpose of his map use is to locate activities and events, which led to the creation of records, and to identify the repositories where those records may be found. The repositories will be determined by the activity or event and will not share the same name necessarily. The example of a street address in Walton-onthe-Hill in 1830 shows how many jurisdictional locations it has had over the next 150 years. A database is being created in Western Australia linking place names and jurisdictions for all communities of 200 or more population; it will also need to incorporate isolated place names. 
The enquirer in framing a request usually does not distinguish between the different sets of information required and the limits inherent in maps due to scale and size. Essentially three maps are required:

1. Small scale showing the major area in which the enquirer's family lived and its geographical relationships to major known locations.

2. Medium scale (1:50 000 to 1:250 000) showing the environment in which the family lived - physiography and topography, lines of communication and commercial centres.

3. Large scale (1:10 000 or larger) showing building details or on which such details can be plotted.

Also required will be boundary, cadastral and other thematic information. Given the temporal changes that have occurred, the need for a wider range of maps is implicit. It is also not always feasible to provide the maps for the reader to do the rest. Some personal readers need map reading and drafting assistance. When providing a remote service, as happens in the Western Australian library service, it is often necessary to provide annotated copies from maps to meet the needs shown above. It is a problem facing all reference librarians as to how far they should go in providing service.

\section{Tools and Strategies for Genealogical Map Reference Work}

Maps are the obvious tools to be found in map libraries. They are often more than they claim to be. Cartographers produce a map for a particular purpose with prime thematic information. This is reflected in the title and the catalogue record. The main information is usually supported by other information to provide a base and context. It is often this secondary information which is the specific detail needed by the map user. The terminology used by the researcher does not correspond to that prescribed by the arbiters of cataloguing practice for place names. The authoritative sources cited in cataloguing manuals are fixed in time and limited to officially approved names. Names given may be corrupted - "Backhill End" turned out to be "at the back of Hillend Farm" and "Churchaasmartin" as "Church House, Marton (Middlesbrough)". Eastern Europe in particular was subject to major boundary and imposed language shifts as Empires flowed and ebbed. Documents I have handled from one region in southeast Poland and the Ukraine have been multilingual.

To cope with these the map library should hold or have access to, as well as current and historical gazetteers and map indexes, topographical dictionaries and histories, travel guides (the $19^{\text {th }}$ century Baedekars I have found extremely useful). There should also be access to a wide range of directories (local and professional) 
and official and university lists and registers. The British War Office issued some useful multilingual gazetteers of Eastern European countries after the Second World War. Toponymical works such as those of the English Place Name Society are also desirable. As more countries are making their official gazetteers and place name indexes available on-line, it is becoming easier, but "How can you look up a word in the dictionary if you don't know how to spell it?" The map librarian must gain some knowledge of the principles of toponymy - especially of place name elements and be able to think laterally to decipher handwritten phonetically spelt names and locate or plot them on maps.

\section{Conclusion - Skills and Outcomes}

Nearly twenty years ago I participated in a workshop on the qualifications required for a map curator. Both library and cartographic/geographic skills were considered essential components, together with physical bibliographic knowledge. To these I now add some specialisation in toponymy. Maps are an information media and may require interpretation to make their contents available to the user - the map librarian must be able to do this. As mentioned, such is the physical make-up of maps that most provide other information in support of their primary theme. It is often this supporting information and interpretation that is required by the researcher. If we are to succeed as gatekeepers on the path to enlightenment, we need to empower ourselves to release the wealth of information for which we care.

\section{References}

Australia. Commonwealth Electoral Act, 1918.

Australia. Committee for Geographical Names in Australia. Toponymic guidelines for Australia. 1993.

Berry, J. F. (comp). Drawing the line. Perth, W.A.: Dept, of Regional Development and the North West, 1990.

Duchemin, Pierre Yves. L'Automation au le Departement des Cartes et Plans. IFLA 1987.

Duchemin, Pierre Yves. OPALINE et le Departement des Cartes et Plans. IFLA 1988.

Joseph, Robert. Beyond boundaries. in Mentelle notes . April 1997.

Lamble, W. H. Do you know your place? or how settled is your settlement? Paper presented to Western Australian Genealogical Society, October 1995. 
Lamble, W. H. Finding your place : maps and other sources of geospatial information. In Newsletter of the Australasian Federation of Family History Societies, June 1997.

Lamble, W. H. Reference services from cartographic collections. In Maps, spatial data and conservation :proceedings of IFLA Malaysian Workshop, University of Malaya, Kuala Lumpur, 17-21 June 1991. Kuala Lumpur, 1992.

Lamble, W. H. The Taxonomy of geographical identification: a pattern for retrieval (A customer focus approach). Unpublished research paper.

United Nations Conference on the Standardization of Geographical Names. 1st. 1967-

Western Australia. Geographic Names Committee. Principles, policies and guidelines

William H. Lamble

112 Rosebery Street

Inglewood

Westwood 6052

Perth, Western Australia

email: wlamble@iinet.net.au 